\title{
Memoria pública y recreación nacional. Políticas de memoria y prácti- cas culturales en la Barcelona republicana (1931-1936)*
}

\author{
Fernando Sánchez-Costa \\ Universidad Internacional de Cataluña
}

RESUMEN: Este artículo tiene como objetivo llevar a cabo una radiografía de los discursos y las prácticas conmemorativas en la Barcelona de la Segunda República (1931-1936). Para ello, utiliza una extensa panoplia de fuentes periodísticas y administrativas de la época, así como bibliografía nacional e internacional. Entiende el autor que la «memoria pública» forma parte de la "esfera pública» en sentido habermasiano, es decir, del ámbito en el que la comunidad se autodescubre y autodefine. Por eso, el autor realiza una disección de las narrativas y de las praxis conmemorativas, a fin de encontrar los implícitos ideológicos que subyacen o se explicitan en ellas. El concepto de "memoria pública» queda perfilado como una categoría de análisis socio-histórico. El texto analiza los discursos de memoria dominantes y su vinculación con el nacionalismo liberal-obrerista imperante. Estudia las concomitancias y las diferencias de estos relatos verbales y visuales con la historiografía catalana renaixentista. Al mismo tiempo, arguye que la partitura básica del imaginario histórico catalán, así como la voluntad de "redimir el pasado», permiten interpretar el comportamiento politico de los dirigentes del periodo. El artículo recoge también la importancia de la iniciativa ciudadana en la configuración simbólica del nuevo tapiz de memoria urbana.

\section{Palabras Clave: Memoria; Memoria pública; Barcelona; Segunda República; Esquerra Republicana de Catalunya; Redención del pasado.}

* Este artículo es fruto de una investigación financiada por el Ministerio de Educación a través de las becas FPU. Las siglas que se utilizarán son: APMB [Actas del Plenario Municipal de Barcelona] y AAB [Archivo Administrativo de Barcelona]. 
Public memory and national recreation. Politics of memory and cultural practices in republican Barcelona (1931-1936)

ABSTRACT: The aim of this article is to analyse speeches and commemorative practices in Barcelona during the Second Republic (1931-1936). For this purpose, it uses a wide range of contemporary newspaper and administrative sources as well as national and international bibliography. The author understands that the "public memory" forms part of the "public sphere» in the Habermassian sense, that is to say of the area in which the community discovers and defines itself. With this aim in mind, the author dissects commemorative narratives and praxis so as to identify the ideologically implicit concepts that underlie or are made explicit within them. The concept of "public memory» is defined as a category of sociohistorical analysis. The text analyses the dominant speeches of memory and their links with the prevailing liberal-working class nationalism. It studies the coincidences and differences between these verbal and visual accounts and renaixentista Catalan historiography. At the same time, it is argued that the fundamental tenets of the Catalan historical mind-set, as well as the wish to "redeem the past», enable us to interpret the political behaviour of leaders in this period. The article also makes reference to the importance of citizen-led initiatives for the symbolic configuration of the new tapestry of urban memory.

KeY WORDS: Memory; Public Memory; Barcelona; Second Spanish Republic; Esquerra Republicana de Catalunya; Redemption of the past.

\section{INTRODUCCIÓN}

Sonaban en las iglesias de Barcelona las campanadas del medio día del 14 de abril de 1931. Anunciaban la hora del ángelus. Sin saberlo, anunciaban también que un viejo ideal, anhelado por muchos españoles como una suerte de tierra prometida ${ }^{1}$, estaba a punto de encarnarse y hacerse realidad: la República. Un grupo nutrido de ediles republicanos recién electos se dirigían hacia el Ayuntamiento. Los encabezaba Lluís Companys, uno de los líderes más destacados de Esquerra Republicana de Catalunya (ERC)2. El partido, formado un mes antes, había ganado contra todo pronóstico las elecciones en

1 No es extraño encontrar descripciones de la República realizadas con gramática y semántica bíblica. En diciembre de 1930, el Comité Revolucionario proclamaba que «para salvarse y redimirse no le queda al país otro camino que el de la revolución». Sobre la pervivencia de los esquemas narrativos católicos en la cultura de memoria republicana -laica, por supuesto-, cfr. SÁNCHEZ-COSTA, 2011: 517-598.

2 Sobre la formación y desarrollo político-doctrinal de ERC durante la Segunda República, cfr. MOLAS, 1972; CULLA, 1977; UCELAY-DA CAL, 1982; IVERN I SALVÀ, 1988. 
las principales ciudades catalanas. Llegó Companys a las puertas del Ayuntamiento, acompañado del séquito que lo flanqueaba. No hallaron resistencia. Alcanzaron el despacho del alcalde gobernativo de Barcelona, Martínez Domingo. Companys, bregado en la lucha política y sindical, le exigió la vara de gobierno de la ciudad. El alcalde en funciones hizo un tímido amago de oposición. Duró poco su resistencia. Entregó la alcaldía a la mayoría republicana triunfante. Companys, arropado por correligionarios de su partido y de otras formaciones republicanas, proclamó la República desde la balconada del Ayuntamiento.

¿Fue el alcalde gubernativo poco gallardo? Es difícil afirmarlo. La Monarquía disponía, en efecto, de suficientes resortes fácticos para detener el golpe recibido en las urnas. Al menos, para aplazar unos meses la decisión final sobre el régimen político en España. Pero ya no tenía fuerza ni confianza moral. A menudo, en la historia, los hechos no suceden porque tengan que acontecer necesariamente, sino porque la mayoría de la población piensa que van a acontecer, sea más o menos objetiva su percepción. Desde 1930, los Republicanos habían ido ganando en España el terreno del discurso y de las emociones ${ }^{3}$. Se habían impuesto en el imaginario ciudadano. La palabra «república» se había convertido en un término mágico, en el que cada cual proyectaba sus sueños político-sociales. La República suponía construir España de nuevo, sin apriorismos ni condiciones. Este carácter mítico que adquirió la república en los meses precedentes a su proclamación facilitó su advenimiento, pero dificultó luego su asentamiento realista y favoreció un clima de pronto desencantamiento ${ }^{4}$. Una vez proclamado el nuevo régimen, los que habían combatido bajo el estandarte republicano levantaron la mirada y descubrieron que, para cada uno de ellos, la bandera por la que habían combatido tenía tonalidades y coloraciones distintas.

La misma tarde del 14 de abril, los regidores republicanos barceloneses se reunieron en el Salón Plenario del Ayuntamiento. Una intensa emoción presidió el encuentro. Jaume Aiguader, elegido por Macià para presidir la Alcaldía, pronunció unas palabras nítidas y vibrantes: «Venimos aquí a constituir el primer Consistorio republicano revolucionario» ${ }^{5}$. Sin duda, si se trató de una revolución, fue atípica, ya que no comportó violencia ni derramamiento de sangre. El hecho, en cualquier caso, es que las nuevas élites republicanas entendieron siempre la ruptura del 14 de abril y el proceso de transformación estructural de la sociedad española consiguiente como un proceso revolucionario. Puede decirse también que los líderes republicanos comprendieron la

3 Cfr. MAURA, 2007: 150-165, 209-210, 221, 275-276.

4 Compárese, por ejemplo, la diferencia de tono entre los editoriales de La Humanitat el 31 de diciembre de 1931 y el 13 de abril de 1932.

5 APMB, 313, 14.IV.1931 (traducción del autor). 
República más como un contenido que como una forma. La República no debía ser simplemente un sistema neutro para regular la convivencia sin tutelas coronadas, sino un intento de reestructurar el estado y la sociedad española de acuerdo a los valores y principios que habían regido la tradición republicana desde el siglo XIX, en una combinación sinérgica de la doctrina liberal con las aspiraciones socialistas ${ }^{6}$.

Dos días más tarde volvió a reunirse el Consistorio. En esta ocasión, estuvieron también presentes los representantes de la Lliga Regionalista, que aceptaron el nuevo régimen. El plenario se celebraba en un momento de tensión entre Barcelona y Madrid. El gobierno catalán y el español mantenían un pulso sobre el estatus de Catalunya en la República recién nacida. Poco después de la alocución de Companys, Francesc Macià había proclamado la República Catalana en el marco de la República Federal Española. Frente a la proclama federal de Macià, los dirigentes estatales sostenían que la estructura territorial de la República debía definirse en las Cortes Constituyentes. La historia es conocida. El carismático líder de Esquerra Republicana aceptó finalmente convertir la República Catalana en la Generalitat de Cataluña. Lo que aquí nos interesa es que una de las primeras decisiones conmemorativas del Ayuntamiento serviría, precisamente, como gesto simbólico de distensión entre Barcelona y Madrid.

Es llamativo que entre los asuntos prioritarios del nuevo Consistorio se contara la reforma del nomenclátor. La ruptura del marco cívico que se había producido debía traducirse en el espacio urbano con inmediatez. El cambio en los nombres de calles es una forma eficaz de pregonar que se ha producido un cambio sustancial en el dominio de la esfera cívica y de indicar cuáles son los nuevos referentes normativos y canónicos en el espacio público ${ }^{7}$. El 24 de abril se constituyó una Comisión para la Revisión del nombre de calles ${ }^{8}$. A

6 La dialéctica entre la comprensión de la República como forma y como contenido es sumamente interesante. Así como se había dado una patrimonialización de España desde el tradicionalismo (Cfr., por ejemplo, DIARIO DE BARCELONA, 1.X.1933: 34; 3.IV.1934: 3; 27.IV.1935: 7; 8.XII.1935: 10; 27.III.1935: 10), se produjo también una patrimonialización de la República desde el republicanismo liberal y socialista. En Cataluña, la Lliga reclamó que la República fuera un régimen de democracia abierta y plural, mientras recriminaba a las izquierdas haberse apropiado del régimen (Cfr. LA VEU DE CATALUNYA, 20.V.1931: 1;14.IV.1932: 1; 15.IX.1932: 1; 14.IX.1933: 1; 17.IX.1933: 10; 26.IX.1934: 1; 12.IV.1936: 11). En La Humanitat, Ferran Valera aseguraba, en cambio, que «la República tiene que ser republicana», arguyendo que había «ciertos postulados esenciales de la República [como] la democracia, la libertad, el laicismo, el poder civil única, la evolución hacia la justicia social y la protección moral y material dispensada a las clases trabajadoras». (LA HUMANITAT, 22.VII.1934: 12; otros ejemplos nítidos de este posicionamiento: LA HUMANITAT, 3.I.1934: 8; 8.XII.1935: 1; 1.I.1936: 1; 13.IV.1936: 1).

7 Cfr. AZARYAHU, 1996.

8 APMB, 313, 24.IV.1931. 
mediados de junio, el Ayuntamiento aprobó la primera gran modificación toponímica. Detengámonos, de momento, en la sesión consistorial del 16.IV.1932. La mayoría municipal decidió trocar el nombre de la actual Diagonal (entonces Avenida de Alfonso XIII), que fue bautizada como Avenida del 14 de abril. En la misma sesión se decidió también que los dos grandes tramos del paseo San Juan fueran bautizados con el nombre de los dos héroes o «mártires de Jaca», Fermín Galán y Ángel García Hernández, fusilados por encabezar la intentona golpista republicana en diciembre de 1930.

Los dos militares serían grandes iconos de la memoria republicana. Los periódicos republicanos contenían cada 14 de diciembre fotografías, elogios y artículos sobre los dos fusilados 9 . Se afirmaba que, con su sacrificio y con su sangre, habían abonado y regado el frondoso árbol republicano. En palabras de Lerroux, «sin el sacrificio romántico y heroico de aquellos capitanes, el alma popular española no se hubiera levantado a expresar su protesta y sus anhelos de mudanza en las elecciones municipales de $1931 »^{10}$. La imposición de su nombre a dos calles de Barcelona se convirtió, en un momento de turbulencia nacionalista, en un gesto de hondo calado político. Así, al menos, quisieron entenderlo los ediles republicanos. Los primeros nombres aprobados por el Ayuntamiento serían para dos personalidades no catalanas. El representante federal Velilla pidió a la prensa que constatará que este gesto proclamaba que «lejos, en las tierras de España, no hay más que hermanos nuestros, que han sufrido por un rey y una misma monarquía, y que hoy, dado que vamos hacia una federación (...) nos damos la mano sin recelo» ${ }^{11}$.

9 La interpretación predominante y canónica de los dos militares, alentada por el republicanismo liberal y socialista, fue que los dos capitanes habían sido precursores de la República. La Humanitat lo resumía: «Fueron héroes y mártires. Al dar su sangre por la causa del pueblo hicieron más fácil y rápida la victoria de este» (LA HUMANITAT, 14.XII.1932: 1. T.A.). Desde la órbita de la Lliga se desdeñó su figura, considerándolo como un ejemplo del fracaso de los métodos revolucionarios. Con el paso de los años y con el país resquebrajado, el director de $\mathrm{La} \mathrm{Veu}$, Joaquim Pellicena, escribió un artículo en el que reinterpretaba sus figuras como símbolo de reconciliación nacional. García Hernández era creyente. Fermín Galán se negó a recibir asistencia espiritual. «En su último abrazo se contenía todo el sentido que ellos daban a la República (...). Una República que fuera la República de todos». (LA VEU, 12.IV.1934: 13. Traducción del autor). Desde el anarquismo se acusaba a los líderes republicanos de conmemorar hipócritamente a dos hombres honestos abandonados a su suerte por los adalides republicanos. (Cfr. SOLIDARIDAD OBRERA: 3.XII.1931: 1; 6.XII.1931: 8; 3.XII.1931: 1).

10 LERROUX, 2009: 117.

${ }^{11}$ Intervenciones de Lluhí y Velilla en el plenario municipal. Cfr. APMB, 313, 16.IV.1931. 


\section{LA MEMORIA PÚBLICA EN BARCELONA (1931-1936): OBJETO Y CONTORNO DE ESTE ESTUDIO}

Tras este ejemplo, podemos empezar a colegir cómo las cuestiones de memoria pública son un escenario privilegiado para el debate y el posicionamiento político. Ésta es, al fin y al cabo, la premisa teórica de la que partimos en este artículo. Al debatir sobre la versión canónica y la representación pública del pasado, la sociedad no está discutiendo tanto sobre los acontecimientos históricos como sobre su presente y su futuro comunal. No se debate la historia. Se discute la metahistoria que la acompaña, la gramática teleológica que la vertebra. El término clave para esta investigación es el de «memoria pública». ¿A qué nos referimos con este concepto?

La memoria pública es una parte importante de la cultura histórica, es decir, del modo en que una sociedad elabora su experiencia temporal, del modo en que conoce, interpreta, objetiva, utiliza y transmite su pasado. El paraguas conceptual, teórico y metodológico de la cultura histórica abarca tanto las prácticas de interpretación y reproducción de la historia en el ámbito privado como en el ámbito público ${ }^{12}$. Este artículo centra el foco de atención en una de sus vertientes: la memoria pública ${ }^{13}$. Lacónicamente, podríamos decir que la memoria pública designa los contenidos y las dinámicas de la cultura histórica que tienen lugar en la esfera pública y guardan una vinculación directa o tangencial con la configuración política de la comunidad y con su posible conciencia nacional ${ }^{14}$.

Bajo la categoría de «memoria pública» englobamos el conjunto de discursos, prácticas y representaciones históricas que tienen lugar en la esfera pública. Esta constelación verbal, ritual y material del recuerdo histórico no es estática ni univoca, sino que se conforma en un diálogo constante entre las distintas culturas de memoria que vertebran los imaginarios sociales. La memoria pública presupone una elaboración interpretativa de la experiencia histórica y se concreta en una dinámica comunicacional de difusión y contestación de narrativas y figuraciones sobre el pasado. La memoria pública no consiste en un contenido de conciencia. Se trata, en cambio, de un sistema objetivado y tangible de representaciones históricas materializadas (material o verbalmente) en el espacio cívico.

Es, por tanto, la «publicidad» o la «proyección pública» de algunos relatos y prácticas de memoria lo que les otorga un rango de memoria pública. Pero

12 Sobre la noción de cultura histórica, cfr. SÁNCHEZ-COSTA, 2009a; 2009b. Uno de los máximos difusores y teorizadores del término «cultura histórica» ha sido Jörn Rüsen. Cfr. RÜSEN, 1994. Cfr. también SÁNCHEZ-MARCOS, 2012: 177-202.

${ }^{13}$ Seguimos, en buena medida, la conceptualización del término propuesta por BODNAR, 1994.

${ }^{14}$ Nuestra teorización de la memoria pública parte de SÁNCHEZ-COSTA, 2011: 83-88. 
el atributo es más específico todavía. Identifica aquellos relatos, prácticas y debates sobre el pasado que, además de tener un carácter masivo, guardan una cierta vinculación con la conformación política e identitaria del grupo social. El acento de esta perspectiva metodológica recae en analizar la pragmática política e identitaria de las narrativas y de las objetivaciones conmemorativas socialmente extendidas. Procura, al menos, determinar los «implícitos» ideológicos que arquitecturan estos relatos históricos.

La investigación sobre la memoria pública no invierte sus esfuerzos en averiguar el rigor o las proposiciones históricas proclamadas, sino en dilucidar qué prácticas del recuerdo sigue una sociedad, qué imágenes del pasado aparecen en el espacio público y qué resonancias o potencialidades políticas contienen. La memoria pública se articula, pues, como un diálogo o dialéctica entre narrativas, representaciones y prácticas históricas concurrentes. Los distintos agentes sociales se afanan por conseguir la hegemonía discursiva y para convertir su planteamiento histórico y su cultura conmemorativa en canónicos. La memoria pública forma parte, pues, del marco racional y comunicativo en el que se autodescubre y autodefine la comunidad, de la «öffentlichkeit» habermasiana.

Un estudio global sobre la memoria pública no debe limitarse a discernir los discursos y las representaciones históricas, sino que debe procurar también radiografiar su infrastuctura y sus dinámicas de elaboración, difusión y recepción ${ }^{15}$. Es necesario atender a la praxis de memoria, a su manifestación visible y litúrgica. De este modo, el análisis de la memoria pública es un camino de investigación que permite adentrarse transversalmente tanto en los imaginarios y en los debates ideológicos de una sociedad como en su estructura, sus relaciones de poder y sus prácticas culturales. Al mismo tiempo, ofrece la posibilidad de abordar la cuestión de la memoria histórica con menor pasión política y mayor rigor académico, al mismo tiempo que permite estudiarla en distintos contextos geográficos y temporales.

Apuntemos ahora las coordenadas temporales y espaciales de nuestro estudio. Nos interesa la memoria pública en la Barcelona de la Segunda República. En realidad, nos centraremos en el periodo 1931-1936. Utilizamos la palabra «Segunda República» en un sentido metonímico, designando una parte por el todo. El periodo republicano no concluyó en Barcelona hasta 1939. Sin embargo, la delimitación temporal propuesta tiene sentido, ya que el estallido de la guerra no supuso simplemente una mutación sustantiva en la vida del régimen republicano sino que, al menos en Barcelona, provocó un cambio notorio con respecto a las políticas de memoria seguidas durante los cinco primeros años de la República ${ }^{16}$.

${ }^{15}$ Cfr. MICHONNEAU, 2002: 314.

${ }^{16}$ Cfr. FABRA / HUERTAS, 1982. 
El espacio de nuestro estudio es Barcelona. Mejor dicho, la esfera pública barcelonesa. En «la esfera pública» incluimos principalmente la opinión pública, la tribuna política y el espacio urbano. Estudiaremos, pues, los discursos de memoria en la prensa barcelonesa del periodo, la utilización de la historia en el ámbito político y las prácticas conmemorativas desarrolladas en las calles de la ciudad. Entre los periódicos, hemos elegido cuatro que representan a sectores distintos de la población barcelonesa de la época. Así, hemos analizado las páginas de La Humanitat (diario oficial del nacionalismo liberal-obrerista encabezado por ERC), La Veu de Catalunya (histórico diario del nacionalismo liberal-conservador comandado por la Lliga) ${ }^{17}$, Solidaridad Obrera (principal órgano de expresión del anarcosindicalismo cenetista) y el Diario de Barcelona (periódico vinculado al españolismo monárquico). Nos centraremos principalmente en La Humanitat y La Veu de Catalunya, ya que eran los órganos oficiosos de las dos fuerzas que copaban el $80 \%$ del Parlamento catalán. Para desentrañar la estructura básica de la narrativa histórica canónica, hemos acudido a libros de texto para las escuelas.

\section{LA ASUNCIÓN CREATIVA DEL DISCURSO HISTÓRICO RENAIXENTISTA}

Sin lugar a dudas, uno de los cimientos más importantes del catalanismo renaciente durante el siglo XIX y consagrado como nacionalismo hegemónico durante el siglo XX ha sido el discurso histórico. De todos modos, la historiografía catalana del siglo XIX no fue nacionalista en el sentido actual del término $^{18}$. La conciencia nacional catalana decimonónica, como bien ha señalado J.M. Fradera, se caracterizó por un doble patriotismo ${ }^{19}$; es decir, por un amor ferviente y creciente a las particularidades históricas e identitarias de Cataluña, al mismo tiempo que por un compromiso claro con el proyecto nacional español. Un proyecto nacional, es cierto, que las élites políticas y culturales catalanas quisieron reformular, para hacerlo más plural. Se llevó a cabo «una lectura catalana del proyecto nacional español» ${ }^{20}$.

Un ejemplo paradigmático de la historiografía catalana de la «Renaixença» es Víctor Balaguer. Liberal convencido, ministro del gobierno de España, dedicó buena parte de su vida a cantar las «glorias catalanas» del periodo me-

17 Todas las citas procedentes de La Humanitat y La Veu Catalunya han sido traducidas por el autor del artículo.

18 Para una valoración panorámica de la historiografía catalana desde el siglo XIX hasta la Segunda República, cfr., entre otros, ANGUERA, 2001; AURELL, 2000; 2001; CANAL, 2005; FRADERA, 2000; MICHONNEAU, 2002; PUJOL, 2000; SIMÓN, 1994.

19 FRADERA 1992; 1999.

${ }^{20}$ FRADERA, 1999: 98. 
dieval y los enfrentamientos con Castilla en la Época Moderna. Fue el encargado de bautizar las nuevas calles del Ensanche barcelonés, donde dibujó una geografía del esplendor medieval catalán y una elegía de los héroes catalanes modernos. Balaguer defendió firmemente una concepción y una historia de España menos castellano-céntrica ${ }^{21}$ y proclamó las loas del pasado catalán y su contribución a la civilización hispánica. Lo hizo, habitualmente, en castellano. Para él, el sistema político catalán medieval — basado en el pacto entre el rey y las cortes - podía considerarse como una figura del sistema liberal, que él defendía. El propio Balaguer reconocía que su producción historiográfica no era completamente «científica», sino más bien una aproximación poética al pasado catalán, que pretendía desempolvar las «bellezas de la historia de Cataluña», situarlas de nuevo en la palestra del imaginario ciudadano, con la idea de que, en el futuro, otros historiadores profundizaran con mayor espíritu crítico en los cuadros históricos que él había pintado mezclando la investigación histórica con el romántico rumor de la leyenda 22.

Conforme fue avanzando el siglo XIX, la historiografía y la conciencia histórica catalanas bascularon del primer interés por el periodo medieval a una focalización creciente en la época moderna, donde se acentuaban las confrontaciones con Castilla. ${ }^{23}$ Esta evolución iba pareja a la consolidación del catalanismo, progresivamente convertido en nacionalismo. El mismo Prat de la Riba reconocía en su obra principal que, para reafirmar la personalidad nacional catalana, había sido necesaria la contraposición dialéctica con Castilla ${ }^{24}$. En cualquier caso, la historiografía renaixentista y noucentista catalana consolidaron un esquema narrativo fundamental de la historia de Cataluña que caló hondamente en todos los sectores del nacionalismo catalán. Este esquema básico que fundamentaba la conciencia histórica catalana $-\mathrm{y}$ también su conciencia nacional y su actitud política - tenía un dibujo simple, en forma de $\mathrm{N}$.

La historia de Cataluña se podía resumir sintéticamente en un primer periodo dorado de nacimiento, pujanza y plenitud nacional. Esta primera época se veía truncada por la llegada de la monarquía castellana Trastámara, que daba comienzo a un periodo de decadencia, reforzado por las pulsiones centralistas de los Habsburgo y alcanzando su momento culminante con la caída de Barcelona el 11 de setiembre de 1714 ante las tropas borbónicas. Finalmente, Cataluña iniciaba un periodo de renacimiento (Renaixença) y de nueva pujanza, que los republicanos considerarían coronado en el periodo republicano. La Renaixença había tenido un primer impulso cultural y económico, que había ido cristalizando progresivamente en una conciencia política. Este esquema estruc-

\footnotetext{
${ }^{21}$ Cfr. BALAGUER, 1885: 4.

${ }^{22}$ Cfr. BALAGUER, 1853: 1.

${ }^{23}$ Cfr. SIMON I TARRES, 1994.

${ }^{24}$ Cfr. PRAT DE LA RIBA, 1979: 44.
} 
tural básico para abordar la historia de Cataluña queda perfectamente corroborado en los libros de textos para niños y jóvenes utilizados durante la República. Una simple ojeada a los índices y a los bloques nos sirve para confirmar que este relato macro-histórico seguía gozando de plena hegemonía ${ }^{25}$.

No nos interesa ahora realizar un repaso de la evolución de la historiografía catalana durante los siglos XIX y XX. Sí creemos importante, en cambio, reseñar algunos de los ejes vertebradores de su discurso, que se han mantenido inalterados y explican algunas de las acciones políticas de los dirigentes catalanes durante la Segunda República. Su actuación, por ejemplo el 6 de octubre, se comprende mejor sobre la partitura narrativa que articula la conciencia histórica catalana.

Un primer lugar común es la comprensión del periodo medieval como una arcadia nacional. Tras la reconquista, Cataluña habría fraguado su personalidad, que habría alcanzado una plenitud desbordante a partir de Jaume I. Cataluña se habría destacado entonces por su avance político, su progreso económico, su desarrollo cultural, su apogeo militar y su dominio de vastos territorios en el Mediterráneo ${ }^{26}$. La historiografía catalana decimonónica había reiterado el carácter innovador del sistema político catalán, considerado protoliberal y protodemocrático ${ }^{27}$. Se afirmaba que Cataluña había sido el primer pueblo liberal y democrático de Europa ${ }^{28}$. Esta idea seguía bien presente durante la República. Cataluña era el pueblo de la libertad por excelencia.

Los padres del catalanismo político habían convergido en reseñar el carácter liberal de los catalanes. Así, Almirall y Prat de la Riba ${ }^{29}$. Durante la República podemos encontrar esta misma aseveración en autores tan dispares como Antoni Rovira i Virgili o Joaquim Pellicena, miembros de ERC y de la Lliga respectivamente. El historiador Soldevilla, en un libro para niños, aseguraba que «nuestro pueblo ha amado siempre la libertad» ${ }^{30}$. En síntesis, el propio Macià afirmaba que «Cataluña ha sido siempre profundamente liberal y democrática, y así aparecía cuando su independencia le permitía presentarse al mundo tal como era ${ }^{31}$. Durante los años treinta, la interpretación más sistemática y completa sobre el carácter liberal del pueblo catalán la realizó el historiador y político Lluis Nicolau d'Olwer en una conferencia titulada: «Del patriotisme i la democràcia en el procés constitucional de la Catalunya anti-

${ }^{25}$ Cfr., por ejemplo, RICART, 1935.

${ }^{26}$ Cfr., por ejemplo, el libro de texto de FONT I SAGUÉ, 1932: 83.

${ }^{27}$ Cfr. BALAGUER, 1858.

${ }^{28}$ Cfr. BOFARULL, 1881: 15.

${ }^{29}$ ALMIRALL, 1994: 58; PRAT DE LA RIBA, 1979: 93;

${ }^{30}$ SOLDEVILLA, 1933: 141. También en un libro escolar escrito podía leerse que «Cataluña llegó a constituir, en plena Edad Media, una verdadera democracia». (TORROJA, 1933: 97).

31 Missatge de Francesc Macià a la Segona Sessió de la Diputació Permanent, 10.IV.1931 (traducción del autor). 
ga ${ }^{32}$. Con tono y rigor académico, Olwer lee la historia de la Cataluña medieval como un gradual despliegue de la democracia en un sistema progresivamente constitucional y liberal.

Al republicanismo le interesaba mucho retomar el discurso de Cataluña como un pueblo esencialmente liberal y democrático. A lo largo del periodo republicano, la novedad consistió, principalmente, en presentarlo también como un pueblo secularmente republicano. Así, en una conferencia pronunciada en el Ateneo de Madrid en 1931, el que luego sería alcalde de Barcelona por ERC, Carles Pi i Sunyer, insistía en que la naturaleza del pueblo catalán era democrática, liberal y republicana ${ }^{33}$. Diversos autores defendieron en las páginas de La Humanitat el largo anclaje del sentimiento republicano en Cataluña ${ }^{34}$. Tuvo mucha resonancia la tesis del erudito monje capuchino Miquel d'Esplugues, quien publicó en 1933 El compromís de Casp. Esplugues se oponía a la tradición historiográfica catalana que había considerado el Compromiso de Caspe como una «iniquidad» que había iniciado la parábola descendiente de Cataluña ${ }^{35}$. Sostenía, en cambio, que el Compromiso de Caspe demostraba que el pueblo de Cataluña era radicalmente amonárquico o republicano. Cataluña había sido una «República coronada» y, mientras fueran respetadas sus leyes y fueros, se sentía ajena a la polémica sobre el apellido del Rey y desinteresada por el pleito dinástico ${ }^{36}$.

Destaquemos todavía tres aspectos más de la conciencia histórica catalana forjada durante la Renaixença y vigente (aunque reformulada) durante la República. En primer lugar, el pactismo o paccionismo. Víctor Balaguer había loado repetidamente el sistema pactista que rigió el tardo-medievo catalán. El rey juraba cumplir las leyes, fueros y constituciones. Entonces, las Cortes juraban fidelidad al rey. Si el rey rompía el compromiso, el pueblo catalán quedaba libre de la fidelidad prometida. Esa sería la argumentación que se utilizaría en 1640 para emprender la guerra de secesión frente a la Monarquía Hispánica. Años más tarde, Vicens Vives consideraría que la cultura del pacto era la médula más radical del espíritu catalán y de su psicología colectiva ${ }^{37}$.

Otra constante en la cultura histórica catalana ha sido y es el tono trágico y martirial. Prat de la Riba se había lamentado en un conocido artículo, que $L a$ Veu de Catalunya publicaba cada año, que la conciencia histórica catalana

32 NICOLAU D'OLWER, 1933.

${ }^{33}$ Cfr. PI I SUNYER, 1994.

${ }^{34}$ En este sentido, encontramos artículos de Rovira i Virgili, Cecili Gasòliba, Ernest Ventós o Carreras Valls. (Cfr., por ejemplo y respectivamente, LA HUMANITAT, 14.IV.1934: 12; 28.XII.1933; 13.IV.1932: 6; 20.VI.1934).

${ }^{35}$ En 1930, Lluis Domènech i Muntaner había publicado el libro La Iniquitat de Casp.

36 ESPLUGUES, 1933: 9.

37 VICENS VIVES, 1969: 110. 
tuviera una mayor querencia hacia los héroes trágicos y derrotados que hacia los personajes constructores y afirmativos ${ }^{38}$. El hecho, sin embargo, es que la cultura histórica catalana desde el tardo-ochocientos hasta la actualidad ha tenido un tinte trágico y holocáustico. No es este el momento de explicar por qué la fecha del once de setiembre de 1714 y la figura de Casanova se han convertido en el epicentro del imaginario histórico-político catalán. Otros autores han recorrido con probidad la génesis de esta conmemoración y su distinta hermenéutica a lo largo de los últimos dos siglos ${ }^{39}$ — desde una interpretación liberal ${ }^{40}$ hasta la lectura nacionalista preponderante a partir de finales del siglo XIX - . El hecho es que, en palabras de Michonneau, «el culto a Casanova» acabó convirtiéndose en «la matriz de interpretación global de la historia catalana» ${ }^{41}$.

Casanova sintetiza bien el foco de interés prioritario de la historiografía catalana desde finales del siglo XIX: el conflicto con Castilla, vivido de un modo épico y martirial ${ }^{42}$. El amor por la patria catalana, que está dispuesto a llegar hasta la entrega de la propia vida. Se trata, pues, de una aproximación a la historia con acentos épicos, de un regusto muy romántico ${ }^{43}$. En la prensa

38 PRAT DE LA RIBA, 1899.

${ }^{39}$ Por ejemplo, ANGUERA, 2008; BALCELLS, 2008; CREXELL, 1985; GONZÁLEZ CALLEJA, 2005; MARTÍNEZ FIOL, 1977; 2005; MICHONNEAU, 2002.

${ }^{40}$ Durante el siglo XIX, la guerra de sucesión se entendió muchas veces en clave liberal, como una lucha entre un modelo absolutista de Estado y un modelo que respetara las «libertades». En su intervención en el debate sobre el Estatut de Cataluña, Azaña retomaría esta interpretación liberal: «el último estado Peninsular procedente de la antigua monarquía católica que sucumbió al peso de la Corona despótica y absolutista fue Cataluña; y el defensor de las libertades catalanas pudo decir, con razón, que él era el último defensor de las libertades españolas». (AZAÑA, 1932: 88).

41 MICHONNEAU, 2002: 240.

${ }^{42}$ La celebración del Once de Septembre fue la fiesta magna de la Barcelona republicana, por encima del 14 de abril. Hasta el españolista Diario de Barcelona reconoce el éxito cívico y político de la jornada. Cabe decir, sin embargo, que algunos sectores sociales se mostraron displicentes ante la celebración y ante la figura de Casanova. el Diario de Barcelona, por ejemplo, criticaba la «manipulación» histórica con que el nacionalismo republicano había releído al personaje. «Casanova luchó en defensa de las tradicionales libertades de Cataluña, pero no contra España. Casanova combatió a un rey, pero no a la Monarquía. Casanova fue, por encima de todo, caballero cristiano». (DIARIO DE BARCELONA, 19.IX.1934: 3). Desde el anarquismo, se caricaturizaba la festividad y se la presentaba como la autocelebreación de unas nuevas élites que habían barrido a las anteriores para engullir sus privilegios. Con su lenguaje siempre vitriólico y punzante, Solidaridad Obrera atizaba: «En Cataluña se ha conseguido ese ideal de todas las clases medias del mundo: que la burocracia asalte el poder y desde él, además de distribuir cargos, enchufes, momios, becas y beneficios, distribuya con largueza fiestas y fiestecillas que festejar, holgando y cobrando al final de mes los saneados estipendios». (SOLIDARIDAD OBRERA, 8.IX.1933: 1).

${ }^{43}$ Para entender la actuación de los dirigentes de ERC durante la República es necesario tener en cuenta el sentido romántico con que vivían la política. Companys reconocía como las responsabilidades de gobierno chocaban con «la inquietud romántica» que le había empujado 
del periodo se recuerdan las gestas de 1640 y 1714, insistiendo siempre en el número inferior de efectivos que disponían las fuerzas catalanas, en su comportamiento heroico y en el panorama apocalíptico a que condujo la derrota de 1714. En el homenaje anual a Casanova, el President Macià recordaba que «a pesar de la desigualdad de fuerzas, a pesar de tener la seguridad de que serían vencidos, no dudaron ni un momento en sacrificar la vida por la patria» ${ }^{44}$. En su discurso de investidura como presidente de la Generalitat, a principios de 1934, Companys adoptó un lenguaje martirial: «Sea lo que sea lo que el futuro me reserve, estoy dispuesto a sacrificar mi vida por Cataluña, por la República y por la libertad $\gg^{45}$. La promesa de Companys engarzaba con lo más genuino de la tradición martirial catalana. Según explicaba un libro de texto, al morir Pere I, su hijo Jaume proclamó «E morí nostre pare, car això ha usat nostre llinatge tostemps, de vencer o morir». ${ }^{46}$

Sostenemos la tesis de que el esquema de fondo que estructuraba la conciencia histórica catalana ofrece algunas claves para entender la actitud de los dirigentes nacionalistas en la crisis de 1934. No afirmamos en absoluto que este paradigma conmemorativo fuera la causa del golpe institucional que dio Companys en octubre de 1934, pero sí que su comportamiento es más fácilmente interpretable si tenemos en cuenta la gramática y la semántica histórica que había empapado la conciencia histórica del catalanismo. Por una parte, los dirigentes catalanes temieron y anunciaron en público que la entrada de las derechas en el gobierno de la República suponía una traición a las esencias del régimen y, al fin y al cabo, implicaba una ruptura del pacto constitucional republicano. Ante esta supuesta ruptura del pacto fundacional del régimen, el gobierno catalán adoptó una postura acorde con algunos tropos comunes de la autoconciencia histórica catalana: Cataluña debía erigirse en baluarte de las libertades en España, Cataluña era y debía ser la avanzadilla del progreso en España, y todo ello debía llevarse a cabo de forma épica, aunque hubiera que pagar el gesto heroico con la vida. Todos estos elementos, clave en la autocomprensión catalana, están presentes en la declaración de Lluís Companys en aquella tarde-noche del 6 de octubre de 1934, proclamando un Estado catalán que duraría sólo una luna. La sombra de Casanova sobrevoló sin duda el Palacio de la Generalitat aquellas horas — entre trágicas y grotescas — de principios de octubre de $1934^{47}$.

toda la vida. (LA HUMANITAT, 15.V.1934: 1). También Marcelino Domingo, pocos antes del golpe revolucionario del 6 de octubre, había reconocido que «nosotros vivimos sujetos a las pasiones románticas, y debemos luchar». (LA HUMANITAT, 15.V.1934: 1).

${ }^{44}$ Cfr. LA HUMANITAT, 12.IX.1932: 4.

${ }^{45}$ Cfr. LA HUMANITAT, 2.I.1934: 3.

46 TORROJA, 1933: 56.

${ }^{47}$ También el alcalde republicano Pi i Sunyer estableció paralelismos entre la actitud numantina de los barceloneses en 1714 y la actitud del gobierno catalán en la crisis de 1934. Cfr. PI I SUNYER, 1975: 284. 


\section{LA REDENCIÓN DEL PASADO}

Defendemos en este artículo la tesis de que una clave importante para comprender la actuación de los líderes republicanos catalanes durante la República fue su voluntad de redimir el pasado. El término de «redención del pasado» lo hallamos por primera vez en tiempos republicanos en el humanista Joan Esterlich, político muy cercano a Cambó. Utiliza la expresión en su libro programático Fènix o l'esperit de la Renaixença, publicado con motivo del Centenario de la Renaixença celebrado en Cataluña durante el año 1933. En este ensayo, que es una propuesta de interpretación del pasado y el futuro de Cataluña en la que se enlazan el humanismo griego, la doctrina cristiana y el pensamiento de Nietzsche, Esterlich arguye que la Renaixença puede entenderse como la redención del pasado desde la voluntad nacional presente ${ }^{48}$. «Es necesario redimir todo lo que ha sido» ${ }^{49}$.

¿Pero qué significa «redimir el pasado»? En primer lugar, salvar el pasado significa rescatarlo de las nieblas del olvido a través del recuerdo. Pero para Esterlich - como también para los principales dirigentes del nacionalismo liberal-obrerista republicano- redimir el pasado comporta, ante todo, dotarlo de un nuevo sentido, justificarlo, resignificarlo a través de la acción presente. Por medio de la praxis contemporánea, unas muertes aparentemente estériles y trágicas, pueden convertirse en semillas de resurrección nacional o de triunfo de una clase. Con la victoria póstuma de la causa, la muerte martirial queda justificada, queda dotada de sentido. Se refiere Esterlich, por ejemplo, a los catalanes caídos en la Guerra de Sucesión. «Por nuestra afirmación actual, por nuestra voluntad de hoy, los rescatamos de sus penas y, a través de estos muros irrefutables que son el tiempo y la muerte, les damos la certidumbre de que su sacrificio no fue inútil» ${ }^{50}$.

La consecución de la autonomía y la proclamación de la República significó para muchos el triunfo definitivo sobre los borbones y la victoria final catalana en la Guerra de Sucesión. Otorgaba un sentido a la muerte holocáustica de aquellos que habían defendido «las libertades catalanas». El triunfo de una república de carácter liberal-socializante justificaba también la vida y la muerte de los precursores de la causa obrera, algunos de los cuales habían sido asesinados en presencia de los líderes que ahora dirigían los destinos de Cataluña. Para entender el debate y el duro enfrentamiento que opuso a ERC y a la Lliga durante buena parte de la República ${ }^{51}$, no debemos olvidar que en

48 ESTERLICH, 1934: 176, traducción del autor.

${ }^{49}$ ESTERLICH, 1934: 74, traducción del autor.

${ }^{50}$ ESTERLICH, 1934: 74, traducción del autor.

${ }^{51}$ El enfrentamiento político entre ERC y la Lliga fue de extrema crispación y duro durante los primeros años republicanos. La confrontación alcanzó su zénit en 1934. Después de 
las divergencias entre los planteamientos y los prohombres de los dos partidos no había sólo discrepancias políticas, sino también largas noches de vela de cadáveres de correligionarios, asesinados durante los turbulentos años del pistolerismo en Barcelona. La memoria pública barcelonesa durante la Segunda República fue una memoria viva y vivida. Quizá sea éste uno de sus aspectos más destacados. Era viva, porque seguía latiendo en la cabeza y en el corazón de los personajes del periodo. Era vivida, porque muchos ciudadanos habían convivido, y algunos combatido en las mismas trincheras, con los personajes que ahora se celebraban ${ }^{52}$. La política y los debates del periodo republicano se hicieron en carne viva, sobre experiencias dolorosas recientes no cicatrizadas del todo ${ }^{53}$.

En cuanto nacionalistas, los dirigentes de ERC se propusieron dar sentido a la muerte de los patriotas de Cataluña caídos por «las libertades» del Principado. Dando un salto mortal en el tiempo, Lluis Nicolau d'Olwer, historiador y político nacionalista republicano, aseguraba que la instauración de la democracia y la recuperación del Parlamento catalán significaba el cumplimiento definitivo de los decretos de las Cortes Catalanas de 1706, donde se proclamaba que Cataluña no pertenecía ni pertenecería nunca a la casa de Borbón ${ }^{54}$. Unos meses antes, al inaugurarse el parlamento de Cataluña, Macià quiso realizar un significativo y denso discurso de resonancias historicistas. Vinculó, como también haría Olwer, los años de 1932 (inauguración del Parlamento) y de 1713-1714. La última sesión de cortes - explicaba el President en su discurso-, celebrada el 5 de julio de 1713, ya no fue presidida por el rey, y fue

las elecciones de 1936 se abrió un periodo de distensión entre las fuerzas políticas catalanas. Algunas referencias al llamado «oasis catalán» durante el periodo las encontramos en artículos del periodista Manuel Brunet en LA VEU DE CATALUNYA, 20.X.1934: 1; 4.III.1936: 11; también, en las memorias del alcalde de Barcelona (1934-1936), PI I SUNYER, 1975: 359.

${ }^{52}$ En las efemérides de las principales figuras del nacionalismo liberal-obrerista, los periódicos afines contenían artículos elogiosos, además de recuerdos de personas que habían vivido con ellos o presenciado su muerte. Companys rememoraba a menudo el día en que conoció la noticia del asesinato de Layret, mientras Matos Barrio detallaba el asesinato del líder político y obrerista, pues lo había presenciado (LA HUMANITAT, 30.IX.1932). El hijo de Salvador Seguí, Helenio, rememoraba el asesinato de su padre, siendo él un niño: «Mi madre, desesperadamente, se me echó al cuello». (SOLIDARIDAD OBRERA, 10.III.1933: 1). El socialista Gabriel Alomar evocaba las horas en el hospital y la muerte de otro líder obrerista, Francesc Comes: «Los que presenciamos este momento terrible, inolvidable, no pudimos contener las lágrimas». (LA HUMANITAT, 10.III.1935: 5, traducción del autor).

${ }^{53}$ Así lo entendía el Conseller de la Generalitat Bonaventura Gassol i Rovira, quien aseguraba que «hay muertes que llenas de paz que dejan sereno. Hay otras que, sólo recordarlas, remueven. Nuestra época está llena de recuerdos de estas muertes. Por eso también nuestros problemas políticos y, de una manera muy especial los sociales, tienen esta viveza que quema». (LA HUMANITAT, 30.XI.1935: 1).

54 NICOLAU D’OLWER, 1933: 22. 
el brazo popular el que impuso y forzó la lucha acérrima contra Felipe V. Una guerra que «no terminó con la victoria de Felipe V». «Nada como la apertura de estas cortes proclama tan claramente que esta guerra la hemos ganado los catalanes $\rangle^{55}$.

También en el campo social, se afirmaba, tenía sentido la sangre vertida por líderes obreros como Seguí o Layret, pues su sangre había dado fruto. Con la implantación de políticas socializantes en el marco republicano, su sacrificio cobraba sentido. Personajes como Pablo Iglesias habían sido redimidos por el brote esplendoroso de la semilla sembrada en su predicación obrerista $^{56}$. Según el político Ernest Ventós, el líder político-sindical Francesc Layret quedaba redimido el 14 de abril, pues «consagraba el triunfo de los ideales por los que siempre había luchado: libertad, Cataluña y República» ${ }^{57}$. También se veía salvado del olvido, de la ignomia y del sinsentido por el recuerdo público que se le rendía. Así lo entendía el historiador Antoni Rovira i Virgili, comentando en un artículo el monumento erigido a Layret. «Los que caen con gloria, en la lucha de las armas o la lucha de las ideas, tienen la recompensa de la resurrección perpetua. (...) Todas las pistolas del crimen no podrán matar el espíritu ni el recuerdo del caído que se endereza con su triple ideario catalán, republicano y social $»^{58}$.

\section{Las PRÁCticas Socioculturales y las políticas de la MEMORIA PÚ- BLICA}

Los estudios de memoria han tendido a centrarse en el análisis semántico del discurso o las representaciones históricas. Recientemente, sin embargo, diversos autores han solicitado una ampliación del foco y han acentuado la importancia de atender a las mediaciones y a la recepción en el análisis de las culturas de memoria ${ }^{59}$. En efecto, la memoria pública es un proceso dialógico y una praxis cultural y comunicativa de primer orden. Los discursos y las representaciones conmemorativas no aparecen en el vacío. Surgen sobre una lógica contextual y pragmática concreta; se desarrollan de acuerdo a unas prácticas políticas, burocráticas y económicas particulares; son, muchas veces, el resultado de la convergencia de múltiples inteligencias y voluntades; están condicionadas por su materialidad expresiva; finalmente, son recibidas

55 MACIÀ, 1932: 6, traducción del autor.

${ }^{56}$ Cfr. COMORERA 1935: 1.

${ }^{57}$ LA HUMANITAT, 30.XI.1931: 6.

${ }^{58}$ LA HUMANITAT, 19.IV.1936: 1.

${ }^{59}$ Cfr., entre otros, ASSMANN, 1992. BORSÒ, 2004. KANSTEINER, 2002. MICHONNEAU, 2002 y WERTSCH, 2007. 
y percibidas de formas muy variables. En este epígrafe nos proponemos precisamente analizar las dinámicas de la memoria pública en la Barcelona republicana.

En primer lugar, debemos consignar que el poder municipal, el Ayuntamiento, fue el principal tejedor del nuevo tapiz de memoria urbana. El Consistorio republicano reafirmó en las ordenanzas municipales su soberanía sobre el espacio público y sobre los nombres de calles ${ }^{60}$. El nuevo nomenclátor se diseñó en las dependencias consistoriales. Hemos apuntado, páginas atrás, la casi inmediata constitución de una comisión política encargada de la revisión de los nombres de calles, que se mantendría en activo hasta 193461. En realidad, esta comisión reemprendió los trabajos de la ponencia creada durante el periodo de transición (1930-1931), que había realizado ya algunos cambios y había empezado a estudiar seriamente otros con sorprendente auda$\mathrm{cia}^{62}$. Ya en periodo republicano, la Lliga propuso en diversas ocasiones una comisión técnica, ajena a los debates e intereses políticos ${ }^{63}$, pero la mayoría republicana rechazó «volver a entregar las iniciativas del ayuntamientos a los técnicos ${ }^{64}$. Muchos de los nuevos nombres de calles fueron propuestos por los regidores en los plenarios semanales. Las propuestas acababan derivándose a la Comisión de Revisión de Nombres de Calles. Al final, todas las modificaciones toponímicas debían ser aprobadas por el plenario municipal.

Ahora bien, queremos insistir en este epígrafe en que el poder político no fue, en absoluto, el único configurador de la catarsis simbólica que vivió la ciudad. Muchas veces, el Ayuntamiento se limitó a ser el canalizador y el tamizador de las múltiples iniciativas que surgían de la sociedad civil. Si atendemos, especialmente, a los nuevos monumentos erigidos en Barcelona, podemos concluir que la mayoría no surgieron de iniciativas municipales, sino de propuestas de la activa sociedad civil barcelonesa. El Ayuntamiento fue, pues, vehiculador y cristalizador de una nueva cultura de memoria que emanaba del tejido asociativo urbano.

Limitémonos a indicar algunos ejemplos que nos permitan comprender los mecanismos de las políticas de memoria. Tomemos como punto de partida la dinámica de la reforma del nomenclátor. Fue práctica habitual que vecinos y

${ }^{60}$ Cfr. Dictamen de la Comisión de Revisión de Nombres de Calles, 24.IX.1932. (AAB, Caja 22433, exp. 24).

${ }^{61}$ En su periodo de máxima actividad (1931-1932), estuvo formada por los miembros de ERC Ernest Ventós, Josep Bertran de Quintana, Joaquim Ventalló y Josep Escofet; por el radical Jesús Ulled, el regionalista Frederic Amat, el republicano conservador Felip Solà de Cañizares y el federal Abel Velilla. (APMB, 314, 6.V.1931: 86).

${ }^{62} \mathrm{La}$ intensa política seguida durante la dicturadura se encuentra bien exlicada en FABRE y HUERTAS, 1982.

${ }^{63}$ Cfr., traducción del autor. APMB, 315, 17.VI.1931: 174.

${ }^{64}$ Cfr., traducción del autor. APMB, 320, 30.X.1931: 169. 
diversos tipos de asociaciones se movilizaran para reclamar el nombre de una calle. Barcelona contaba con una red asociativa muy activa. Durante los años de la Segunda República, las asociaciones nacionalistas - especialmente de izquierdas - demostraron una gran influencia en la vida cívica y en la reconfiguración del paisaje simbólico de la ciudad. De ellas nacería, por ejemplo, los proyectos de monumento a Francesc Layret y al doctor Martí i Julià, inaugurados en la primavera de 1936 y que hoy continúan erigiéndose como principales vestigios de la memoria republicana en las calles de Barcelona.

Los archivos municipales guardan decenas de propuestas de variación toponímica que distintos grupos de vecinos hicieron llegar al Consistorio. En el verano de 1931, por ejemplo, 150 vecinos de la calle de la Concordia, enviaron una misiva al Ayuntamiento solicitando la remoción y la recuperación de su antigua denominación, «Setge del $1714 »^{65}$. Encontramos propuestas sorprendentes, como la de un catalán residente en París que, haciendo gala del tópico de la tacañería catalana, pedía al ayuntamiento que optara por los nombres breves, a fin de ahorrar dinero en el envío de telegramas ${ }^{66}$. Sin embargo, la mayor parte de las peticiones para variar el nombre de una vía no procedían de grupos de vecinos, sino de agrupaciones y asociaciones políticas, culturales y periodísticas. De nuevo, renunciamos a presentar un elenco de muestras ${ }^{67}$. Particularmente significativa fue la movilización que, en 1934, llevó a un buen grupo de asociaciones nacionalistas a lograr que el nombre de Sabino Arana bautizara una nueva calle de la ciudad ${ }^{68}$.

Entre las asociaciones que solicitaron cambios onomásticos podemos sumar, también, colegios de periodistas, asociaciones juveniles, ateneos populares, lógicas masónicas y casales de ERC en el extranjero ${ }^{69}$. Sin embargo, quizá la campaña más espectacular y llamativa fue la que organizaron múltiples asociaciones esperantistas de Europa encabezadas por Federació Esperantista de Catalunya i Balears. El Consistorio barcelonés guarda postales y cartas enviadas por defensores y difusores del esperanto en Bélgica, Francia, Inglaterra, Holanda, Alemania, Italia, Austria y Hungría ${ }^{70}$. Finalmente, el 14 de

${ }^{65}$ Carta firmada el 25 de junio de 1931. AAB, caja 22434, exp. 50.

${ }^{66}$ CLAVELL, 30.V.1931.

${ }^{67}$ El lector podrá encontrar algunos ejemplos en SÁNCHEZ-COSTA 2011; 2012.

${ }^{68}$ Creemos interesante anotar cuáles fueron estas asociaciones, ya que se cuentan entre las más activas en las acciones de reforma simbólica de la ciudad: Unió Catalanista, Palestra, Joventut Nacionalista de Barcelona, Partit Nacionalista Català, Partit Nacionalista Republicà d'Esquerra, Joventut La Falç, Joventut Catalanista Republicana, Nosaltres Sols, Joventuts d'Esquerra Estat Català, Pàtria Nova, Associació Protectora de l'Ensenyança Catalana, Unió Democràtica de Catalunya y L'Intransigent.

${ }^{69}$ Cfr., correspondientemente, AAB, caja 22434, exp. 65; Ibid. 49; Ibid. exp. 65; APMB, 338, 30.IX.1932: 108; AAB, caja 22434, exp. 59;

${ }^{70}$ Cfr. AAB, caja 22434, exp. 53. 
abril de 1932 se abrió una calle en memoria del doctor Zamenhof y en honor del esperanto, buena síntesis del carácter internacionalista, fraternal y utópico en que había derivado una rama de la Modernidad.

Las inauguraciones de calles y monumentos suponían, además de las grandes jornadas conmemorativas como el Once de Septiembre o el Catorce de Abril, uno de los principales teatros de la memoria urbana. Los rótulos con el nombre de las calles fueron el vértice de teatros de la memoria, el punto focal de entarimados del recuerdo. El descubrimiento de placas o la inauguración de monumentos eran ocasiones propicias para canonizar un determinado referente de memoria, proclamar unos valores concretos, celebrar el triunfo de unos principios socio-políticos y reunir a la comunidad que los sostenía. Era, también, un momento de autocelebración de las élites socio-políticas imperantes y una oportunidad para reivindicar la propia autoridad, demostrar el poder y revestirse de prestigio ${ }^{71}$. Estos actos eran, al fin y al cabo, liturgias políticas y dramaturgias del poder. Seguían una misma pauta ritual.

El Ayuntamiento se encargaba de costear el marco teatral de la función (la tarima, las flores y la banda municipal). Los vecinos se sumaban al «decorado» engalanando sus balcones con banderolas. Los asistentes blandían estandartes de su agrupación. La banda municipal amenizaba el acto con música. No faltaba nunca el Cant dels Segadors ${ }^{72}$. Este himno - de resonancias belicosas, heroicas y emocionantes - fue el trasfondo musical de la memoria pública y de la actividad política del periodo. Sonaba, con inquebrantable entusiasmo, en todos los eventos conmemorativos. En el momento previsto, llegaban los organizadores y las autoridades. Les recibían los aplausos y los acordes musicales. Tenían lugar, posteriormente, las alocuciones de los organizadores y dirigentes, facilitadas por la megafonía. El clímax de la celebración llegaba al descorrer el velo que cubría la lápida. Muchas veces, se trataba de un plafón especial, diseñado artesanalmente y con algunos motivos decorativos especiales. Las autoridades se retiraban en loor de multitud, de nuevo al son de los acordes musicales.

No sólo las placas urbanas y los monumentos fueron polos de atracción de los eventos conmemorativos. También ocupó un lugar destacado el cementerio. Desde un punto de vista antropológico, es interesante constar cómo las personas suelen encontrar en los huesos de los difuntos, una remanencia de su presencia. El sarcófago de Macià se convirtió en un lugar obligado de culto para el nacionalismo progresista ${ }^{73}$ y los nichos de Layret, Seguí o el doctor

${ }^{71}$ Cfr. GUTIÉRREZ VIÑUALES, 2004. MICHONNEAU, 2002.

72 Sobre la historia del Cant dels Segadors y el papel de la Guerra dels Segadors en la cultura histórica catalana, cfr. BALCELLS, 2008. GARCÍA CÁRCEL, 1982. GONZÁLEZ CALLEJA, 2005. SIMON I TARRÉS, 1994 y VIDAL, 1991.

${ }^{73}$ Bonaventura Gassol se negó a que los restos de Macià fueran retirados de Barcelona para ser llevados a Poblet, a un panteón de catalanes ilustres. Explicaba, en 1935, que la pre- 
Martí i Julià fueron también escenario de movilizaciones conmemorativas. Durante el año 1935, con la Generalitat suspendida, la visita a la tumba de Macià, así como el homenaje en el cementerio a Layret y Seguí, se convirtieron en grandes actos de afirmación republicana y nacionalista ${ }^{74}$. Por otra parte, cada agosto, la tumba de Prat de la Riba recibía visita y tributo de los dirigentes del nacionalismo conservador.

Sostenemos también que los nombres de calles sirvieron como medio para canalizar el dolor público, para dar sentido - desde las instituciones - a un hecho siempre tan desconcertante como la muerte. Así, al morir más o menos insospechadamente algunos de los ediles del Consistorio o alguna figura relevante de la sociedad catalana, el Plenario decidía muchas veces otorgar su nombre a una calle. Frente a la muerte, frente a la constatación de la común fragilidad humana, desaparecían las barreras ideológicas, y los enemigos políticos aunaban sus voluntades para conmemorar a un antiguo compañero o a un personaje significante de la cultura catalana ${ }^{75}$. Era una forma de dar respuesta a su desaparición, proclamando - con la consagración de la fama- la fecundidad de su vida y la perennidad de su obra. Al fin y al cabo, se trataba de una forma secular de redimir la muerte a través del recuerdo.

Hay un aspecto sustantivo en el estudio de las culturas de memoria habitualmente omitido: la recepción. Sin embargo, es crucial analizar la recepción de los discursos y signos conmemorativos. Al fin y al cabo, el objetivo de toda acción conmemorativa es transmitir un mensaje. Pero, ¿se logra siempre? ¿Hasta qué punto asumen los ciudadanos los mensajes que promueven los responsables conmemorativos? Tampoco en este trabajo pretendemos describir el grado y el modo de recepción de la memoria institucional entre los ciudadanos barceloneses. Presentaremos simplemente algunos datos significativos y, sobre todo, constataremos cómo la ciudadanía no fue una simple

sencia de sus restos en Barcelona era imprescindible para poder mantener vivos los rescoldos del republicanismo progresista que el gobierno procuraba yugular (LA HUMANITAT, 27.XI.1935: 1). La visita a la tumba de Macià se convirtió en «una tradición inventada». En la primavera de 1934, una delegación político-militar japonesa de visita en Barcelona se aproximó a honrar los restos de Macià (DIARIO DE BARCELONA, 16.V.1934: 11). En 1936, Miss Cataluña iría a ofrendar su premio al presidente difunto. La tumba de Macià llegó a ser también un lugar de peregrinación para los dirigentes de ERC tras las grandes victorias, como la lograda en las elecciones municipales de 1934 y en las generales de 1936.

${ }^{74}$ En diciembre de 1935, desfilaron ante la tumba de Layret casi 16.500 ciudadanos, fueron depositadas 2.725 ofrendas florales y trescientos pueblos de toda Cataluña estuvieron representados (Cfr. LA HUMANITAT, 2.XII.1935: 3). La movilización no era espontánea. Había sido Companys quien, desde la prisión, había pedido a las bases que, en su nombre, fueran a depositar un «ramo de laurel» sobre la tumba de Layret. «Fue mi maestro, mi amigo, mi jefe», escribió desde la prisión. (Cfr. LA HUMANITAT: 20.XI.1935: 1).

${ }^{75}$ Cfr. APMB, 315, 17.VI.1931; APB, 341, 2.XII.1932: 34. 
receptora de narrativas conmemorativas textuales y visuales. No sólo contribuyó a diseñarlas. También se opuso a las que consideró desacertadas.

Una cosa era el frenesí transformador de los responsables de la memoria y otra bien distinta su plasmación en las vías urbanas. El Ayuntamiento se encontraba en un momento de asfixia económica ${ }^{76}$ y una reforma a fondo del nomenclátor - incluyendo la catalanización de todas las placas - no era una cuestión económicamente baladín ${ }^{77}$. No sólo fue imposible llevar a cabo una catalanización de todos los rótulos, sino que tampoco las calles con un nombre nuevo experimentaron una rápida mutación en sus lápidas. De este modo, convivieron durante varios años dos tapices de memoria en el espacio urbano. En julio de 1932, un concejal denunciaba que seguían colgando en la Plaza de la República - el lugar donde estaban emplazados el Ayuntamiento y la Generalitat - algunos rótulos con el antiguo nombre de «plaza de la Constitución ${ }^{78}$. En 1933, la actual Diagonal albergaba todavía señales con el nombre de Alfonso XIII. Si en estos lugares destacados no se había producido una completa reforma de la rotulación, podemos imaginar lo que acaecería en otras calles menos importantes.

En ocasiones, los ciudadanos barceloneses respondieron críticamente y se movilizaron contra algunas propuestas conmemorativas. La voluntad del ayuntamiento republicano de proceder a una importante remodelación toponímica, encontró diversos frentes de oposición. La Lliga defendió una reforma más puntual y menos ideológica. Algunas entidades relevantes de la sociedad civil cuestionaron la política onomástica del consistorio ${ }^{79}$. También desde la prensa conservadora se fustigó la praxis toponímica republicana ${ }^{80}$. Entre 1931 y 1936 se produjeron tres casos que suscitaron un especial revuelo. Nos referimos a la polémicas en torno al nombre de la calle Princesa (cuyo nueva denominación oscilaba entre Pablo Iglesias y Rusiñol), a la discusión sobre la conveniencia de sustituir el nombre de la calle Bisbe Claret por el de Mutualitat y al nuevo nombre de la calle Fernando. Estos casos propiciaron diversas iniciativas ciudadanas, como visitas al ayuntamiento de personajes influyentes, manifiestos ciudadanos y extensas recogidas de firmas. Hemos

\footnotetext{
${ }^{76}$ Sobre la situación económica del Ayuntamiento de Barcelona entre 1931 y 1936 y su influjo en las políticas municipales, cfr. ALQUÉZAR, 1986.

${ }^{77}$ Se conservan documentos referentes a concursos municipales para placas toponímicas en AAB, serie Q, caja 6, sig. 22433.

${ }_{78}$ Cfr. APMB, 335, 27.VII.1932: 85.

${ }^{79}$ Por ejemplo, el Ayuntamiento recibió misivas críticas con la política onomástica (por su precipitación y sesgo ideológico), del Centre Excursionista de Catalunya (15.VII.1931) y de la Associació d'Arquitectes de Catalunya (26.VIII.1931). Los dos documentos se encuentran en AAB, caja 22434, exp. 49.

${ }^{80}$ Cfr., por ejemplo, el editorial del DIARIO DE BARCELONA, 27.VIII.1933: 3.
} 
tratado estos casos en otro artículo ${ }^{81}$. Ciñámonos ahora a la última de las controversias, alrededor de la calle Fernando.

La calle Fernando era una de las más populares y turísticas de la ciudad. Era conocida por los establecimientos donde se vendían productos típicos españoles como, por ejemplo, mantones de manila. La dictadura le había devuelto el nombre de Fernando VII. Durante el gobierno de transición se había limado la denominación, circunscribiéndola a Fernando. Fuera como fuera, el nuevo consistorio no estaba dispuesto a que una de las calles centrales del casco antiguo tuviera un nombre de resonancias monárquicas y absolutistas. La Comisión propuso el nombre de Fivaller, personaje venerado por el catalanismo por haberse opuesto en el siglo XV a las pretensiones absolutistas sobre Barcelona del rey Trastámara que regía la Corona de Aragón ${ }^{82}$. La decisión acarreó desde el principio una gran controversia. Pronto, la Agrupación de Vecinos emitió un sutil manifiesto mostrando su rechazo a la propuesta ${ }^{83}$.

El Ayuntamiento, mientras tanto, recibió diversas cartas de vecinos y comerciantes de la calle a favor y en cambio del nombre ${ }^{84}$. El propietario de una óptica afirmaba que, "como catalanista republicano de izquierdas, vería con gran disgusto que se atendiera la solicitud de estos señores monárquicos disfrazados» ${ }^{85}$. Al mismo tiempo, un centenar de barceloneses procedentes de diversos barrios firmaron un documento a favor del cambio de nombre. Ante el barullo organizado, el Consistorio tomó una decisión insólita en las políticas de memoria barcelonesas. Decidió convocar un referéndum entre los vecinos de la calle. La estrategia se torció. Aunque de forma ajustada, el nombre de Fernando se impuso en la votación ${ }^{86}$. La Comisión de nombres de calles, sin embargo, resolvió dar definitivamente a la calle el nombre de Fivaller. El republicanismo había podido comprobar por primera vez el riesgo de las urnas.

\section{EL DISCURSO CONMEMORATIVO NACIONAL-OBRERISTA}

Hay concomitancias sustantivas entre la hermenéutica de Cataluña realizada desde la órbita de ERC y desde el ámbito de la Lliga. Al fin y al cabo y a pesar de sus modulaciones, el discurso de ambos partidos sobre Cataluña tie-

81 SÁNCHEZ-COSTA, 2012.

${ }^{82}$ Cfr. la viva narración del episodio en BALAGUER, 1853: 14.

${ }^{83}$ Cfr. Manifiesto firmado el 15.VI.1931. AAB, caja 22434, exp. 52.

${ }^{84}$ Las cartas se conservan en AAB, caja 22434, exp. 52.

${ }^{85}$ Carta de Pelai Morell, 12.VI.1931, traducción del autor. AAB, caja 22434, exp. 52.

${ }^{86} \mathrm{El}$ referéndum se celebró el 19.IX.1931. Votaron 258 vecinos y se abstuvieron 73 . El nombre de «Fernando» obtuvo 126 votos. «Fivaller», reunió 112. «Ferran» se llevó 12 votos y «Fernando VII», 6. 
ne un corte netamente herderiano y organicista. En ambos partidos encontramos expresiones como «el alma de Cataluña», «el genio de Cataluña», etc. Esta clase de frases serían quizá más previsibles en el nacionalismo conservador, que bebe de La Tradició Catalana de Torras i Bages y de la Nacionalitat Catalana de Prat de la Riba, donde aparece la idea del «espíritu» catalán, entendido como forma cultural del pueblo ${ }^{87}$. Pero podemos constatar cómo también Bonaventura Gassol habla de «la Cataluña inmortal de siempre» ${ }^{88}$, Pi i Sunyer no tiene escrúpulos en referirse «al alma del pueblo de Cataluña» ${ }^{89}$ y Rovira i Virgili afirma que «Cataluña es una unidad espiritual, un alma, una identidad vital perenne que tiene en el idioma su máxima expresión colectiva» ${ }^{90}$.

También en su relación con la historia y la tradición, el nacionalismo liberal-conservador y liberal-obrerista guarda importantes similitudes. A pesar de las diatribas de Aiguader contra la tradición ${ }^{91}$ y de la defensa, por parte de Rovira i Virgili ${ }^{92}$, de que la voluntad del pueblo debe imponerse siempre sobre las inercias de la tradición, lo cierto es que en su praxis y en su discurso, los líderes de ERC apelaron constantemente al pasado y a la historia de Cataluña. Tanto los representantes de la Lliga como los de ERC mantenían que Cataluña debía ser fiel a su esencia y a su tradición histórica, acomodándola a los tiempos contemporáneos. La divergencia no se producía tanto a la hora de señalar el papel que debía jugar la tradición en la Cataluña presente y futura, sino en determinar cuál era el quicio de la tradición catalana. Mientras que desde el nacionalismo conservador se invocaba, siguiendo a Torras i Bages, que en la médula de la tradición catalana estaba el cristianismo y que, por tanto, era una aporía ser un buen catalanista y renegar de la cultura cristiana ${ }^{93}$, desde la izquierda se argumentaba que el cristianismo era una parte accesoria de la tradición y del alma de Cataluña, en cuyo centro se encontraba el espíritu liberal. Por eso, Nicolau d'Olwer podía argüir que los catalanistas liberales podían ser progresistas y tradicionales al mismo tiempo, porque la verdadera tradición de Cataluña era la libertad ${ }^{94}$.

También el esquema interpretativo con el que se leía la historia de Cataluña era muy similar en ambas riberas del nacionalismo. Nos hemos referido a ello anteriormente. Sin embargo, este armazón hermenéutico común que fundamentaba la conciencia nacional catalana se resquebrajaba al llegar el perio-

87 TORRAS I BAGES, 1981: 29 y PRAT DE LA RIBA, 1979: 49 y 62.

${ }^{88}$ Cfr. LA HUMANITAT, 26.V.1936: 12.

${ }^{89}$ PI I SUNYER, 2001.

${ }^{90}$ Cfr. LA HUMANITAT, 14.IV.1935: 1.

${ }^{91}$ Cfr. AIGUADER, 1930.

${ }^{92}$ Cfr. ROVIRA I VIRGILI, 1932: 50.

${ }^{93}$ Cfr., en este sentido, el artículo publicado por Carles Cardó en LA VEU DE CATALUNYA, 17.V.1935: 10.

${ }^{94}$ Cfr. NICOLAU D’OLWER: 192. 
do contemporáneo y el siglo XX. La memoria más reciente de los dos nacionalismos era diferente $\mathrm{y}$, muchas veces, violentamente opuesta. De hecho, la memoria más reciente consistía en el recuerdo del enfrentamiento político y social del catalanismo liberal-conservador alineado con la burguesía y el catalanismo liberal-progresista, que había prestado su apoyo y su voz al movimiento obrero. Las dos alas del nacionalismo se habían visto también vivamente enfrentadas por la cuestión religiosa.

Parte de la memoria republicana en Barcelona consistió en reivindicar los antiguos referentes históricos del nacionalismo catalán, como Casanova o Clarís. Pero el nacionalismo liberal-obrerista imperante, comandado por ERC, quiso también instaurar una nueva cultura de memoria, con una clara función pragmática. A este nuevo relato conmemorativo - plasmado en nombres de calles y en monumentos - podemos bautizarlo como nacional-obrerista. Tenía una clara función pragmática. Debía servir para vindicar los valores de una república liberal de inclinación socializante. En esta línea cabe destacar el gran monumento a Pi i Margall (y a la República) que, tras interesantes debates arquitectónicos, políticos, circulatorios y estéticos ${ }^{95}$, se levantó al final del Paseo de Gracia, en el cruce con la Diagonal. Pero, ante todo, este nuevo universo conmemorativo se propuso reivindicar el catalanismo de resonancias sociales o el sindicalismo de acento catalán. Es posible encontrar una triple motivación pragmática en la elección de este programa simbólico. Por un lado, la reivindicación de la propia ERC y de sus valores. El partido se enorgullecía y presentaba como principal galón el haber logrado unir la causa nacional catalana y la causa de la emancipación obrera. Los monumentos levantados a Francesc Layret y al doctor Martí i Juliá tuvieron como objetivo honrar a los «precursores» de un catalanismo comprometido con la cuestión social. A través de estos monumentos, no sólo se proclamaban los principios de ERC, sino que, de rebote, quedaban prestigiados sus dirigentes ${ }^{96}$. A través

${ }^{95}$ El debate más importante en el Consistorio sobre el monumento a Pi i Margall se produjo el 11.IX.1931 y está ampliamente recogido en APMB, 321. La historia es rocambolesca y merecería un artículo aparte. Un gran escultor catalán —-Miquel Blay- había diseñado ya un monumento, que tenía prácticamente acabado. Sin embargo, diversos concejales se opusieron al proyecto por considerarlo excesivamente «modernista». Finalmente, los arquitectos municipales se encargaron de delinear un proyecto alternativo: un gran pináculo coronado por una escultura representando a la República. No se inauguró hasta la primavera de 1936. El Ayuntamiento franquista resemantizó el conjunto monumental modificando diversos atributos (como la escultura). Actualmente, el pináculo ha sido despojado de todo elemento simbólico.

${ }^{96}$ Esta legitimación a través de la memoria queda patente en el caso del monumento a Francesc Layret, líder catalanista republicano de principios del siglo XX. Companys había sido uno de sus colaboradores aventajados. El vínculo entre el personaje conmemorado y el presidente de la Generalitat fue proclamado tanto en la colocación de la primera piedra (I.V.1934) como en la inauguración del monumento (19.IV.1936). El día de la inauguración, 
de esta política conmemorativa, como hemos apuntado páginas atrás, quedaban redimidos y reivindicados estos personajes. También, esta memoria era, implícitamente, una lanzada contra la Lliga y contra el anarcosindicalismo.

Frente a una Lliga que supuestamente se había desentendido del problema social para concentrarse en la cuestión nacional y en el desarrollo capitalista, ERC vindicaba y celebraba a los catalanistas que habían procurado dar un tono social al nacionalismo. Al mismo tiempo, este nuevo relato de memoria servía para reivindicar un esquema axiológico y político distinto al que sostenía el anarcosindicalismo, que durante la República se vio muy influido por las tesis maximalistas, revolucionarias y ajenas al nacionalismo catalán imperantes en los cuadros de la FAI. Se produjo una interesante divergencia hermenéutica entre ERC y la CNT a la hora de conmemorar a algunos líderes obreristas que habían tenido relación más o menos directa con el catalanismo político. Desde el nacionalismo liberal-obrerista se celebró, por ejemplo, a Salvador Seguí, como un ejemplo de líder sindical posibilista y abierto a la entente con los partidos políticos. Un antiguo líder sindical, A. Castellà, afirmaba en La Humanitat que «con la muerte de Seguí, el grupo faista de la CNT puede satisfacer sus aspiracions de apoderrse de las fuerzas obreras catalanas $\gg{ }^{97}$. Desde Solidaridad Obrera, en cambio, se consideraba que ERC se estaba apropiando de un personaje que en realidad, había odiado la política y había sido su víctima ${ }^{98}$.

Uno de los grandes referentes de la nueva memoria promovida por ERC fue Francesc Layret, impulsor de la Unió Federalista Nacionalista Republicana (un partido con similitudes importantes con ERC). En los últimos años de su vida - antes de ser asesinado - había defendido como abogado a obreros cenetistas. Para los dirigentes de ERC, Layret representaba un obrerismo que entendía que la mejor manera de defender los intereses del proletariado no era la acción revolucionaria compulsiva, sino una conquista del poder a través de la participación política. Layret era, pues, un «hombre ejemplar, altísimo precursor del actual florecimiento democrático de Cataluña» ${ }^{99}$. En esta misma línea podía situarse el doctor Martí i Julià. Como presidente de la Unió Catalanista, había procurado abrir el catalanismo al socialismo. El monumento al líder catalanista (situado en el cruce entre la Diagonal y la Ronda del Mig) se erige desde 1936. Durante el franquismo, solamente fue modificada su lápida. La escultura, encargada a Dunyac, tiene una clarísima inspiración noucentis-

\footnotetext{
Ángel Pestaña aseguraba que «vemos aquí al honorable presidente de la Generalitat, señor Lluís Companys, continuador de su obra política (...)». (LA HUMANITAT, 21.IV.1936: 1).

${ }^{97}$ LA HUMANITAT, 11.III.1934: 3. En un sentido similar, LA HUMANITAT, 10.III.1932: 1; 1.III.1934: 8; 11.III.1934: 3.

${ }^{98}$ Cfr. SOLIDARIDAD OBRERA, 10.III.1932: 8.

${ }^{99}$ LA HUMANITAT, 30.XI.1932: 3.
} 
ta. Martí i Julià había sido médico, filántropo y político. El nacionalismo democratizante y socializante del médico se caracterizaba, además, por su tono pacífico y sereno, por lo que se podía oponer tanto al conservadurismo de la Lliga como al radicalismo revolucionario de la $\mathrm{CNT}^{100}$.

Con la introducción de esta memoria del nacionalismo obrerista o del obrerismo de acento catalán, cerramos este artículo sobre la memoria pública en la Barcelona republicana. Hemos podido comprobar cómo los nuevos dirigentes políticos republicanos - espoleados por una fuerte red asociativa civil- llevaron a cabo una activa política de memoria, que por un lado asumió creativamente la cultura conmemorativa catalana desarrollada desde la Renaixença, al mismo tiempo que impulsó un nuevo relato de memoria cívica, con la intención de proclamar los nuevos valores del republicanismo catalanista dominante y de legitimar a sus dirigentes. Hemos podido asomarnos también a algunas prácticas culturales que constituyen la infraestructura de la memoria pública. Nos han quedado diversos asuntos en el tintero. Por ejemplo, la dialéctica entre la memoria republicana y la memoria católica ${ }^{101}$, la permanencia de un discurso conmemorativo de corte españolista ${ }^{102}$, el establecimiento de un nuevo calendario festivo republicano ${ }^{103}$ y la cultura de memoria del anarquismo ${ }^{104}$. También estos paradigmas conmemorativos tejen el tapiz de memoria pública que se vivió en Barcelona durante los primeros años treinta. Esperamos tratarlos en artículos próximos, para tener así una visión más completa de los contenidos y las prácticas de memoria que articularon parte de la vida política, social, cultural y religiosa de la Segunda República en la Ciudad Condal.

\section{BibLIOGRAFÍA}

Almirall, Valentí, Lo catalanisme. Barcelona, Edicions 62, 1994 [1886].

Alquézar, Ramón, L'Ajuntament de Barcelona en el marc del Front d'Esquerres, Barcelona, Columna, 1986.

Anguera, Pere, «Españolismo y catalanidad en la historiografía catalana decimonónica», Hispania, 209 (2001), 907-931.

Anguera, Pere, L'Onze de Setembre. Història de la Diada (1888-1938), Barcelona, Publicacions de l'Abadia de Montserrat, 2008.

100 Cfr. LA HUMANITAT, 18.VI.1932: 3; 30.V.1933: 3; 19.VI.1933: 5; 23.VI.1936: 1 y

12 ;

${ }^{101}$ Cfr. SÁNCHEZ-COSTA, 2011: 571-621.

${ }_{102}$ Cfr. SÁNCHEZ-COSTA, 2011: 398-420.

${ }^{103}$ Cfr. SÁNCHEZ-COSTA, 2011: 485-516.

${ }^{104}$ Cfr. SÁNCHEZ-COSTA, 2011: 622-640. 
Assmann, Jan, Das kulturelle Gedächtnis, München, C.H. Beck, 2005.

Aurell, Jaume, «Historiadores 'románticos' e historiadores 'científicos' en la historiografía catalana contemporánea», Memoria y civilización, 3 (2000), 237-273.

Aurell, Jaume, «La formación del imaginario histórico del nacionalismo catalán, desde la Renaixença al Noucentisme (1830-1930)», Historia Contemporánea, 22 (2001), 257-288.

Azaña, M. y Ortega y Gasset, J., Dos visiones de España. Discursos en las cortes constituyentes sobre el Estatuto de Cataluña, Barcelona, Galaxia Gutemberg, 2005.

Azaryahu, Maoz, «The Power of commemorative Street Names», Environment and Planning, 14 (1996), 311-330.

Balaguer, Víctor, Bellezas de la historia de Cataluña. Barcelona, Imprenta de Narciso Ramírez, 1853.

Balaguer, Víctor: La libertad constitucional. Barcelona, Imprenta de Jaime Jepús 1858.

Balaguer, Víctor, Historia de Cataluña. Madrid, Imprenta de Manuel Tello, 1885 [1860].

Balcells, Albert, Llocs de memòria dels catalans, Barcelona, Proa, 2008.

Bodnar, John, Remaking America. Public Memory, Commemoration and Patriotism in the Twentieth Century, Princeton University Press, 1994.

Borsò, V. y Kann, C. (eds.), Geschichtsdarstellung. Medien, Methoden, Strategien. Wien, Böhlau, 2004.

Canal, Jordi (ed.), «El nacionalismo catalán; mitos y lugares de memoria». Número monográfico de la revista Historia y politica: ideas, procesos y movimientos sociales, 14 (2005).

Crexell i Playà, Joan, El monument a Rafael Casanova. Barcelona, El Llamp, 1985.

Culla, Joan, El Catalanisme d'Esquerra (1928-1936), Barcelona, Curial, 1977.

Esplugues, Miquel, El Compromís de Casp. Barcelona, Altes Impressor, 1933.

Esterlich, Joan: Fènix o l'esperit de la Renaixença, Barcelona, Biblioteca Catalana d'Autors Independents, 1934.

Fabre, J. y Huertas, J.M., Carrers de Barcelona. Com han evolucionat els seus noms, Barcelona, Edhasa, 1982.

Font i Sagué, Norbert: Història de Catalunya, Barcelona, Editorial Altés, 1933 [1899].

Fradera, Josep Maria, Cultura nacional en una societat dividida: patriotisme $i$ cultura a Catalunya (1838-1868), Barcelona, Curial, 1992.

Fradera, J.M., «El proyecto liberal catalán y los imperativos del doble patriotismo», Ayer, 35 (1999), 87-100.

Fradera, J.M., «La política liberal y el descubrimiento de una identidad distintiva de Cataluña (1835-1865)», Hispania, 205 (2000), 673-702.

García Cárcel, Ricardo, «Pau Claris: un mite rentable», L’Avenç, 50 (1982), 54-58.

González Calleja, Eduardo, “'Bon cop de falç’: mitos e imaginarios bélicos en la cultura del catalanismo», Historia y política: ideas, procesos y movimientos sociales, 14 (2005), 119-164. 
Gutiérrez Viñuales, Monumento conmemorativo y espacio público en Iberoamérica, Madrid, Cátedra, 2004.

Kansteiner, Wulf, «Finding Meaning in Memory : a Methodological Critique of Collective Memory Studies», History and Theory (May 2002), 179-197.

Macià, Francesc, El President Macià en el seus textos (1931-1933), Barcelona, Generalitat de Catalunya, 2005.

Maura, Miguel, Así cayó Alfonso XIII, Madrid, Marcial Pons, 2007 [1962].

Martínez Fiol, David, «Creadores de mitos. El 'onze de setembre de 1714' en la cultura política del catalanismo (1833-1939)», Manuscrits, 15 (1997), 341-361.

Ivern i Salvà, Ma Dolors, Esquerra Republicana de Catalunya (1931-1936), Publicacions de l'Abadia de Montserrat, 1988.

Lerroux, Alejandro, La pequeña historia de España (1930-1936), Madrid, Akrón, 2009.

Michonneau, Stéphane, Barcelona: memòria i identitat. Monuments, commemoracions i mites, Barcelona, Eumo, 2002.

Molas, Isidre: El sistema de partits politics a Catalunya (1931-1936), Barcelona, Ed. 62, 1972.

Nicolau d'Olwer, Lluís: Del patriotisme i la democràcia en el procés constitucional de la Catalunya antiga, Barcelona, Imprenta de Nagsa, 1933.

Pellicena, Joaquim, El nostre imperialisme, Barcelona, Sarrià A.G., 1930.

Pi i Sunyer, Carles, La República y la Guerra, México, Oasis, 1975.

Pi i Sunyer, Carles, El alma cordial de Catalunya, (Conferencia en el Ateneo de Madrid, 2.VI.1931). Barcelona, Edició de Francesc Vilanova, 1994.

Prat de la Riba, Enric, La nacionalitat catalana, Barcelona, Edicions 62, 1978 [1906].

Pujol, Enric, Ferran Soldevila i la historiografia catalana del seu temps (18941971). Tesis Doctoral. Universitat Autònoma de Barcelona, 2000.

Ricart Lafont, Damià: Història de Catalunya per a les escoles primàries, Barcelona, Miquel Salvatella Editor, 1935.

Rüsen, J., Füssman, K, Grütter, H. (eds.), Historische Faszination. Geschichtskultur heute. Köln, Böhlau, 1994.

Sánchez-Costa, Fernando, «Cultura histórica y nombres de calles: aproximación al nomenclátor de Barcelona y Madrid», Memoria y Civilización, 9 (2009a), 217-251.

Sánchez-Costa, Fernando, «La cultura histórica: una aproximación diferente a la memoria colectiva», Pasado y Memoria: Revista de Historia Contemporánea, 8 (2009b), 267-288.

Sánchez-Costa, Fernando, «Los mapas de la memoria. Nombres de calles y políticas de memoria en Barcelona y Madrid», Hispania Nova, 12 (2009c).

Sánchez-Costa, Fernando, Memòria pública i debat polític a Barcelona (1931-1936). L'Esquerra Republicana i la Lliga Catalana davant el passat i el futur de Catalunya, Tesis doctoral, UIC, 2011. 
Sánchez-Costa, Fernando, «Street names, politics of memory and social debate in Republican Barcelona (1931-1936): A theorethical reflection and case study», Catalan Journal of Communication and Cultural Studies, 4-1 (2012), 3-19.

Sánchez Marcos, Fernando, Las huellas del futuro. Historiografía y cultura histórica en el siglo $X X$, Barcelona, Editorial UB, 2012.

Simon i Tarrés, Antoni, «Els mites històrics i el nacionalisme català», Manuscrits, 12 (1994), 193-212.

Soldevila, Ferran, Història de Catalunya. Primeres lectures, Barcelona, Associació Protectora de l'Ensenyança Catalana, 1933.

Torras i Bages, Josep, La tradició catalana, Barcelona, Edicions 62, 1981 [1892].

Torroja, Ramon, Història de Catalunya per a nois $i$ noies, Barcelona, Impremta Elzeviriana, 1933.

Ucelay-Da Cal, Enrique, La Catalunya populista. Imatge, cultura i política en l'etapa republicana, Barcelona, La Magrana, 1982.

Vicens Vives, Jaume, Notícia de Catalunya, Barcelona, Ed. Destino, 1969 [1954]

Vidal, Jordi, «La Guerra dels Segadors: mite i historia», L'Avenç, 150 (1991), 40-61.

Wertsch, James V., Voices of Collective Remembering, Cambridge University Press, 2007.

Recibido: 23/10/2012

Aceptado: 10/05/2013 